\title{
Inflammatory immune response in recipients of transcatheter aortic valves
}

Cecilia Veraar, MD, ${ }^{\mathrm{a}, \mathrm{b}}$ Matthias Koschutnik, MD,${ }^{\mathrm{c}}$ Christian Nitsche, MD, ${ }^{\mathrm{c}}$ Maria Laggner, PhD, ${ }^{\mathrm{b}, \mathrm{d}}$

Dominika Polak, $\mathrm{PhD},{ }^{\mathrm{e}}$ Barbara Bohle, $\mathrm{PhD},{ }^{\mathrm{e}}$ Andreas Mangold, $\mathrm{MD}, \mathrm{PhD}, \mathrm{MBA},{ }^{\mathrm{c}}$

Bernhard Moser, MD, PhD, MBA, ${ }^{d}$ Julia Mascherbauer, MD, ${ }^{\mathrm{c}, \mathrm{f}}$ and Hendrik J. Ankersmit, MD, MBA ${ }^{\mathrm{b}, \mathrm{d}}$

\section{ABSTRACT}

Objective: Transcatheter aortic valve implantation (TAVI) is rapidly replacing cardiac surgery due to its minimal invasiveness and practicality. Midterm immunological studies on the biocompatibility of galactose-alpha-1,3-galactose ( $\alpha$-Gal)carrying bioprosthetic heart valves for TAVI are not available. In this study we investigated whether bioprosthetic heart valves employed for TAVI augment an $\alpha$-Gal-specific antibody-dependent and antibody-independent immune response 3 months after TAVI implantation.

Methods: This prospective observational study included 27 patients with severe aortic valve stenosis undergoing TAVI and 10 patients with severe mitral valve regurgitation treated with a transcatheter MitraClip (Abbott Laboratories, Abbott Park, III) procedure. Blood samples were drawn before and 90 days after treatment at a routine checkup. Serum samples were analyzed using enzyme-linked immunosorbent assay. Serum concentrations of $\alpha$-Gal-specific immunoglobulin (Ig) G, IgG subclasses and IgE, complement factor 3a, NETosis-specific citrullinated $\mathrm{H}_{3}$, and the systemic inflammation markers soluble suppression of tumorigenicity and interleukin 33 were evaluated.

Results: Three months after TAVI, we found significantly increased serum concentrations of $\alpha$-Gal-specific IgG3, complement factor complement factor 3a, citrullinated $\mathrm{H}_{3}$ levels, and soluble suppression of tumorigenicity $(P=.002, P=.001$, $P=.025$, and $P=.039$, respectively). Sensitization of $\alpha$-Gal-specific IgE antibodies occurred in $55 \%$ of all patients after TAVI.

Conclusions: Our results indicate that TAVI elicits a midterm, specific humoral immune response against $\alpha$-Gal and causes an unspecific humoral inflammation compared with patients undergoing MitraClip implantation. This observation will lead to a better understanding of postintervention morbidity and the long-term durability of bioprostheses and indicates that caution is appropriate when designing implantation strategies for younger patients. (JTCVS Open 2021;6:85-96)

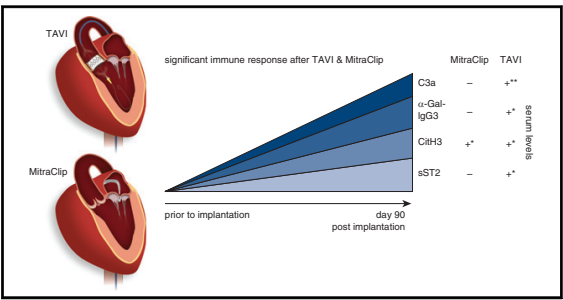

Significant immune response after transcatheter aortic valve implantation (TAVI) and MitraClip (Abbott Laboratories, Abbott Park, III). Three months after TAVI we found significantly increased serum concentrations of galactose-alpha-1,3-galactose $(\alpha-$ Gal-specific $\left.\lg \mathrm{G}_{3}\right)$, complement factor $3 \mathrm{a}$ ( $\left.\mathrm{C}_{3} \mathrm{a}\right)$, citrullinated $\mathrm{H}_{3}$ (citH3), and soluble suppression of tumorigenicity ( $\mathrm{SST}_{2}$ ) levels compared with baseline levels $(P=.002, P=.001, P=.025$, and $P=.039)$. Three months after MitraClip implant, citH3 levels were significantly elevated compared with baseline levels $(P=.03)$

\section{CENTRAL MESSAGE}

Transcatheter aortic valve im-

plantation induces an $\alpha$-Gal-spe-

cific humoral immune response

and augments the complement

activities NETosis and ST2 within

90 days of valve implantation.

\section{PERSPECTIVE}

Next-generation transcatheter aortic valve implantation, deficient for Gal, will show whether immune activity can be dampened with the potential consequence of increased valve durability.

See Commentaries on pages 97 and 99.

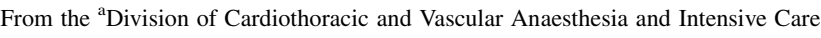
Medicine, Department of Anaesthesiology, General Intensive Care, and Pain Medicine, ${ }^{\mathrm{L}}$ Laboratory for Cardiac and Thoracic Diagnosis, Regeneration and Applied Immunology, ${ }^{\mathrm{c}}$ Division of Cardiology, Department of Internal Medicine II, and Departments of ${ }^{\mathrm{d}}$ Thoracic Surgery and ${ }^{\mathrm{e}}$ Pathophysiology and Allergy Research, Medical University of Vienna, Vienna, and ${ }^{\mathrm{f}}$ Department of Internal Medicine III, University Hospital St. Pölten, Karl Landsteiner University of Health Sciences, Krems, Austria.

Supported by the institutional surgical research facility ARGE Ankersmit (FOLAB Chirurgie) and the Austrian Research Promotion Agency (Vienna, Austria; grant No. APOSEC 862068; 2015-2019) and the Vienna Business Agency (Vienna, Austria; grant No. APOSEC to clinic 2343727).
}

Received for publication Feb 15, 2021; accepted for publication Feb 22, 2021 available ahead of print April 12, 2021

Address for reprints: Hendrik J. Ankersmit, MD, MBA, Department of Thoracic Surgery, Laboratory for Cardiac and Thoracic Diagnosis, Regeneration, and Applied Immunology, Medical University of Vienna, Waehringer Guertel 18-20, 1090 Vienna, Austria (E-mail: hendrik.ankersmit@meduniwien.ac.at). 2666-2736

Copyright $(2021$ The Author(s). Published by Elsevier Inc. on behalf of The American Association for Thoracic Surgery. This is an open access article under the CC BY-NC-ND license (http://creativecommons.org/licenses/by-nc-nd/4.0/). https://doi.org/10.1016/j.xjon.2021.02.012 


\begin{tabular}{|ll|}
\hline Abbreviations and Acronyms \\
$\alpha$-Gal & $=$ galactose-alpha-1,3-galactose \\
$\mathrm{BHV}$ & $=$ bioprosthetic heart valve \\
$\mathrm{C} 3 \mathrm{a}$ & $=$ complement factor 3a \\
$\mathrm{CitH} 3$ & $=$ citrullinated H3 \\
$\mathrm{DAPI}$ & $=4^{\prime}, 6$-diamidino-2-phenylindole \\
$\mathrm{ELISA}$ & $=$ enzyme-linked immunosorbent assay \\
$\mathrm{Ig}$ & $=$ immunoglobulin \\
$\mathrm{IL}$ & $=$ interleukin \\
$\mathrm{mAb}$ & $=$ monoclonal antibody \\
$\mathrm{NET}$ & $=$ neutrophil extracellular traps \\
$\mathrm{NT}-$ proBNP & $=$ N-terminal pro-brain natriuretic \\
& peptide \\
$\mathrm{sST} 2$ & $=$ soluble suppression of \\
& tumorigenicity-2 \\
TAVI & $=$ transcatheter aortic valve \\
& implantation \\
\end{tabular}

$\square$ Video clip is available online.

Transcatheter aortic valve implantations (TAVI) performed by cardiologists and cardiac surgeons will outnumber conventional cardiac operations in the future due to their minimal invasiveness, practicality, and the aging population. ${ }^{1-3}$ However, midterm immunological studies on the biocompatibility of galactose-alpha-1,3-galactose ( $\alpha$-Gal)carrying bioprosthetic heart valves (BHV) for TAVI have not been performed so far.

The $\alpha$-Gal epitope is widely accepted as the major elicitor in the pathogenesis of immune activation after xenotransplantation and implantation of glutaraldehyde-fixed BHVs. The relationship between tissue $\alpha$-Gal-specific immune reactivity and dystrophic calcification, inflammation, and leaflet tearing in bioprostheses in vivo is widely accepted. ${ }^{4-7}$

Beside $\quad \mathrm{BHV}$-induced $\quad \alpha$-Gal-specific antibodydependent humoral immune responses, xenografts activate the classical pathway of the complement system when antibodies bind to antigens such as $\alpha$-Gal on their surfaces, and thereby trigger $\mathrm{C} 1 \mathrm{q}$ to activate $\mathrm{C} 1 \mathrm{r}$ and $\mathrm{C} 2 \mathrm{~s}$, cleave $\mathrm{C} 4$ and $\mathrm{C} 2$ and form $\mathrm{C} 4 \mathrm{~b} 2 \mathrm{a}$ ( $\mathrm{C} 3$ convertase), and activate complement factor $3 \mathrm{a}(\mathrm{C} 3 \mathrm{a}) .{ }^{8,9}$

Most recently, another deleterious immune activation process in xenotransplantation has gained prominence, namely the ejection of DNA-histone complexes into the extracellular space from activated neutrophils to form neutrophil extracellular traps (NETs). ${ }^{10,11}$ Increased NET formation is well known in various clinical conditions, including sepsis, trauma, autoimmune diseases, deep vein thrombosis, atherosclerosis, and thrombotic microangiopathy. ${ }^{12,13}$
Because multiple nosologies share humoral and cellular activation pathways, we asked whether TAVI increases circulating soluble suppression of tumorigenicity-2 (sST2) and its counterpart interleukin (IL)-33, a known biological alarmin that would serve as an additional biological marker for ongoing inflammatory processes. ${ }^{14-16}$

In this study, we investigated for the first time whether BHVs employed for TAVI augment an $\alpha$-Gal-specific humoral immune response of total immunoglobulin (Ig) G, IgG subclasses, and IgE; activate the complement system via $\mathrm{C} 3 \mathrm{a}$; induce citrullinated $\mathrm{H} 3(\mathrm{CitH} 3)$ as a marker for NET formation; and initiate the IL-33/ST2 pathway within 90 days after intervention compared with baseline levels. Patients receiving a MitraClip (Abbott Laboratories, Abbott Park, Ill) procedure served as controls (Figure 1 and Video 1).

\section{METHODS \\ Ethics Approval}

Ethics approval was obtained from the Institutional Ethics Committee of the Medical University of Vienna (EK 2218/2016) during June 2019. All experiments were performed in accordance with the approved ethical guidelines. Written informed consent was obtained from all study participants.

\section{Study Design and Patients}

This work was designed as a prospective, observational, single-center study. Twenty-seven consecutive patients with severe aortic valve stenosis and 10 patients with severe mitral valve regurgitation undergoing TAVI or MitraClip procedures between March and August 2019 at the Department of Cardiology of the General Hospital Vienna (Medical University of Vienna) were prospectively analyzed. We excluded pregnant women, patients who were younger than age 18 years, and patients who did not give written informed consent. TAVI was performed in a hybrid operating room under general anesthesia or conscious sedation. Blood samples were drawn before the procedure and 90 days thereafter at a routine clinical check-up.

\section{Enzyme-Linked Immunosorbent Assays}

Microtiter plates (Maxisorp, Nunc, Denmark) were coated with Gal $\alpha 1.3-G a 1 \beta 1-4 G l c N A c-B S A$ (Dextra Laboratories, Reading, United Kingdom). Optimal coating concentrations of each protein were defined in preliminary experiments. Blocking was carried out using assay buffer (2.5 g human serum albumin, $500 \mathrm{~mL}$ phosphate buffered saline $-/-$, $250 \mu \mathrm{L}$ Tween 20). Sera were diluted in phosphate buffered saline with $0.05 \%$ Tween- 20 and $0.5 \%$ human serum albumin as follows: for $\mathrm{IgE}$, 1:2; for IgG, 1:50; and for IgG1, 3, and 4, 1:20. After sample incubation and washing, the following horseradish peroxidase-conjugated detection antibodies were added: antihuman IgG-Fc (Sigma-Aldrich Corp, St Louis, Mo), IgG subclasses (Sigma-Aldrich Corp) and alkaline phosphatase-conjugated anti-human IgE (BD Bioscience Pharmingen, San Diego, Calif). A color reaction was obtained with peroxidase reagent tetramethylbenzidine (Sigma-Aldrich Corp) and the optical density was read at $450 \mathrm{~nm}$ using an absorbance microplate reader (Infinite F50; Tecan, Männedorf, Switzerland). ${ }^{17}$

A human C3a (BMS2089) enzyme-linked immunosorbent assay (ELISA) kit (Invitrogen; Camarillo, Calif) was used for the quantitative detection of C3a following the manufacturer's instructions. Serum samples were diluted 1:50000 in assay buffer.

Cayman's CitH3 (Clone 11D3) ELISA kit (Cayman Chemical, Ann Arbor, Mich) was used to measure citH3 serum concentrations. The 
Inflammatory immune response in Transcatheter Aortic Valve Implantation and MitraClip recipients
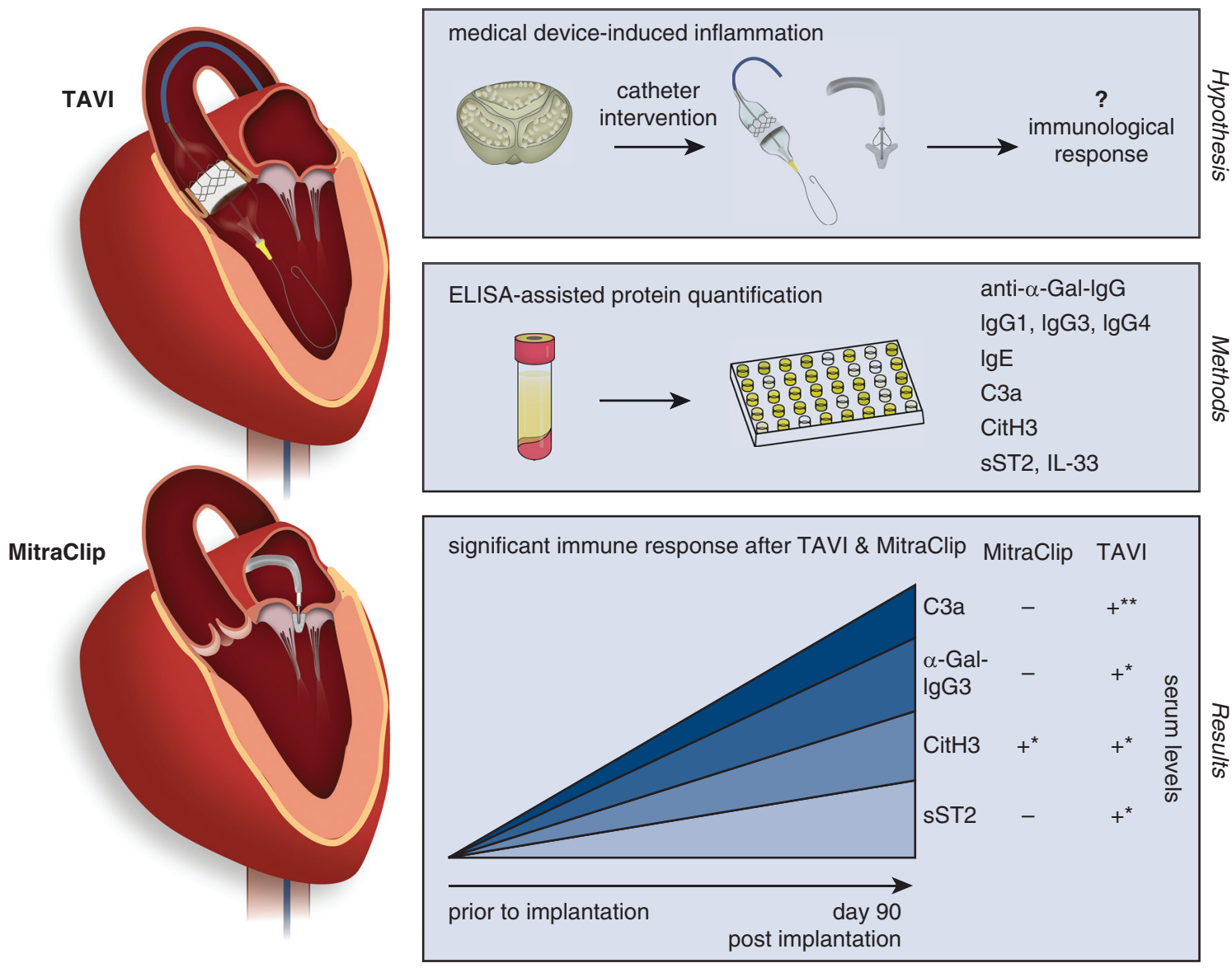

$\alpha-\mathrm{Gal}$ Gal $=$ galactose-alpha-1,3-galactose, $\mathrm{C} 3 \mathrm{a}=$ complement factor $\mathrm{C} 3 \mathrm{a}, \mathrm{CitH} 3=$ citrullinated histone $\mathrm{H} 3, \mathrm{lg}$

$=$ immunoglobulin, IL-33 = interleukin-33, sST2 = solube suppresion of tumorigenicity-2, *indicates $P<.05$,

** indicates $P<.01$

FIGURE 1. Inflammatory immune response in transcatheter aortic valve implantation (TAVI) and MitraClip (Abbott Laboratories, Abbott Park, Ill) recipients. Hypothesis: Biological medical devices for TAVI induce an galactose-alpha-1,3-galactose ( $\alpha$-Gal)-specific antibody dependent and antibodyindependent immune response 3 months after implantation. Methods: Serum samples were drawn before and 90 days after TAVI and MitraClip and analyzed for $\alpha$-Gal-specific immunoglobulin (Ig) G, IgG subclasses, IgE, complement factor 3a (C3a), citrullinated H3 (CitH3), soluble suppression of tumorigenicity-2 (sST2), and interleukin (IL)-33 using the enzyme-linked immunosorbent assay technique. Results: Significant immune responses were observed after TAVI in C3a, $\alpha$-Gal-specific IgG3, citH3, and sST2 and MitraClip in citH3. - indicates no significance; + indicates significance.

microwell plate was coated with a monoclonal antibody (mAb) specific for histone $\mathrm{H} 3$ (citrullinated at R2, R8, and R17). Sera were added in a 1:2 dilution in assay buffer.

To assess SST2 and IL-33 serum concentrations, commercially available ELISA kits for sST2 (DY523B) and IL-33 (DY3625B) (R\&D Systems, Minneapolis, Minn) were used. Sera were diluted 1:20 for sST2 and not diluted for IL-33.

\section{Postinterventional Antithrombotic Therapy}

According to our institutional guidelines patients after TAVI/MitraClip procedure received dual antiplatelet therapy combining aspirin and a P2Y12 receptor inhibitor for 3 months, followed by lifelong daily lowdose aspirin $(100 \mathrm{mg})$. In patients with preexisting anticoagulant therapy phenprocoumon or nonvitamin $\mathrm{K}$ antagonist oral anticoagulants were continued at a therapeutic dose.

\section{Statistical Analysis}

Before the study, we performed a power analysis using $\mathrm{G}^{*}$ Power (Heinrich Heine University, Dusseldorf, Germany) according to a prior publication of our study group on $\alpha$-Gal-specific IgG immune responses after surgical bioprosthetic valve implantation. ${ }^{5}$

To reveal a power of $99 \%, \alpha=0.05,2$-sided, using the Wilcoxonsigned-rank test for matched pairs 27 patients undergoing TAVI were required. To calculate the size of the control group, the Wilcoxon-MannWhitney $U$ test was used. To reach a power of $84 \%, \alpha=0.05,2$-sided, we required 10 patients undergoing the MitraClip procedure.

Graphical methods (histograms) were employed to test normality. Data are reported as mean \pm standard deviation for normally distributed data and median (25th percentile, 75 th percentile) for nonnormal distributions. The Kruskal-Wallis rank test and Mann-Whitney $U$ test were used for nonnormally distributed data and $t$ tests were performed for 


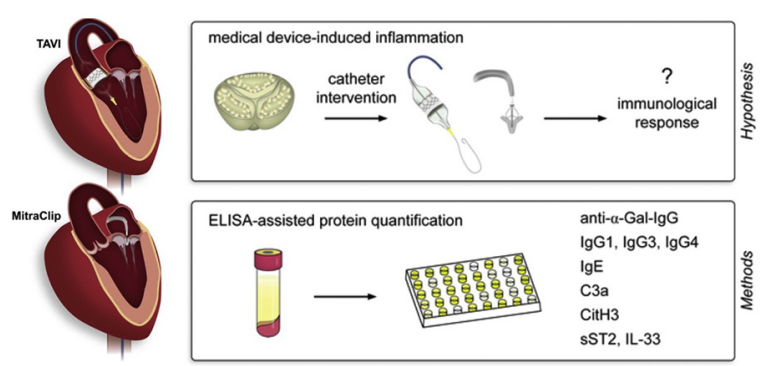

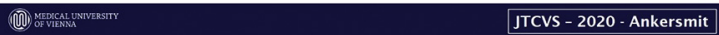

VIDEO 1. Inflammatory immune response in transcatheter aortic valve implantation (TAVI) recipients. Background: Clinical data on xenograft valve durability; galactose-alpha-1,3-galactose ( $\alpha$-Gal)-specific xenograft immune responses in cardiac surgery; $\alpha$-Gal induced meat allergy and cardiac surgery. Study results: $\alpha$-Gal xeongraft immune response in TAVI recipients, inflammation in TAVI recipients: soluble suppression of tumorigenicity-2 (sST2), NETosis, complement. Video available at: https://www.jtcvs.org/article/S2666-2736(21)00056-5/fulltext.

parametric data. The level of statistical significance was set at .05 (2tailed $P$ values). Statistical analyses were performed using SPSS software version 26 (IBM-SPSS Inc, Armonk, NY). GraphPad Prism 8 (GraphPad Software, La Jolla, Calif) was employed for data visualization (boxplots and line diagrams). Boxplots were designed as follows: box, first to third quartile; bar, median; whiskers, fifth to 95th percentile; all individual values are presented as dots.

\section{Data Availability}

All data generated or analyzed during this study are included in this article and Tables E1 through E4.

\section{RESULTS}

\section{Demographic and Clinical Data}

In our study, we enrolled 27 TAVI and 10 MitraClip patients, of whom $13(48.1 \%)$ TAVI and $2(20 \%)$ MitraClip patients were women. The median age of all patients was 78 years (range, 75-83 years) for TAVI and 76 years (range, 68-82 years) for MitraClip patients. Thirty-seven percent of all TAVI patients received bovine and $63 \%$ received porcine heart valves. The implanted medical devices are described in detail in Table E1. Left-ventricular ejection fraction increased and the concentration of $\mathrm{N}$-terminal pro-brain natriuretic peptide (NT-proBNP) decreased statistically significantly in patients receiving TAVI 3 months after intervention $(P=.033$ and $P=.050$, respectively). Detailed baseline characteristics and clinical and echocardiography data are depicted in Tables 1 and 2. Inflammatory conditions in patients with hyperlipidemia and adult-onset diabetes mellitus are depicted in Tables E2 and E3. None of our patients experienced meat allergy before undergoing the TAVI/MitraClip procedure. Three patients had an allergy to penicillin, 1 patient was allergic to ciprofloxacin and 1 patient was allergic to band-aid.
TABLE 1. Demographic data

\begin{tabular}{lccc}
\hline \multicolumn{1}{c}{ Characteristic } & TAVI & MitraClip* & $\boldsymbol{P}$ value \\
\hline Baseline characteristics & & & \\
Age (y) & $78(75,83)$ & $76(68,82)$ & .216 \\
Female & $13(48.1)$ & $2(20.0)$ & .153 \\
BMI & $27.4(23.9,30.0)$ & $24.5(22.0,31.1)$ & .428 \\
Hypertension & $20(74.1)$ & $8(80.0)$ & 1.000 \\
Diabetes & $15(55.6)$ & $3(30.0)$ & .269 \\
Hyperlipidemia & $15(55.6)$ & $7(70.0)$ & .481 \\
Atrial fibrillation & $9(34.6)$ & $5(55.6)$ & .432 \\
COPD & $5(18.5)$ & $0(0)$ & .295 \\
CAD & $19(70.4)$ & $8(80)$ & .694 \\
Smoker & $5(18.5)$ & $2(20.0)$ & .958 \\
Bioprosthetic features & & & \\
Bovine tissue valve & $10(37)$ & - & - \\
Porcine tissue valve & $17(63)$ & - & - \\
\hline
\end{tabular}

Continuous, nonparametric values are presented as median (25th percentile, 75 th percentile) based on Kruskal-Wallis test; categorical variables are presented as $\mathrm{n}$ (\%) based on $\chi^{2}$ test. TAVI, Transcatheter aortic valve implantation; BMI, body mass index; $C O P D$, chronic obstructive pulmonary disease; $C A D$, coronary artery disease. *Abbott Laboratories, Abbott Park, Ill.

\section{Augmented $\alpha$-Gal-Specific IgG3 3 Months After TAVI}

We investigated whether BHVs of a glutaraldehyde-fixed $\alpha$-Gal-bearing scaffold installed via TAVI induce $\alpha$-Galspecific $\operatorname{IgG}$ and $\operatorname{IgG}$ subclasses (IgG1, IgG3, and $\operatorname{IgG} 4$ ) before and 3 months after catheter intervention.

We found significantly increased $\alpha$-Gal-specific IgG3 serum concentrations in patients 3 months after TAVI compared with baseline levels $(P=.002)$. Furthermore, we observed there is a trend toward augmented $\alpha$-Gal-specific $\operatorname{IgG}$, but not $\operatorname{IgG} 1$ or $\operatorname{IgG} 4$ (IgG, $P=.09$; IgG1, $P=.344$; and $\mathrm{IgG4}, P=.279)$. Neither $\alpha$-Gal-specific IgG nor IgG subclasses (IgG1, IgG3, or IgG4) significantly increased in the MitraClip control cohort (Table 3).

Three months after TAVI, $\alpha$-Gal-specific IgE serum concentrations did not increase statistically significant $(P=.284)$. However, IgE sensitization occurred in 55\% of all TAVI patients. Differences in $\alpha$-Gal-specific antibodies between bovine and porcine heart valves for TAVI are shown in Table E4.

\section{Significantly Increased C3a in TAVI Patients 3 Months After Intervention}

The role of the complement system as innate immunity in xenograft rejection beyond naturally occurring cytotoxic $\alpha$ Gal-specific mAbs is well described. Activation of the classical complement pathway is caused by the binding of antibodies to antigens and is the major mechanism of xenograft rejection. ${ }^{8}$ We investigated whether BHVs for TAVI trigger systemic complement activation in vivo. We measured C3a because this protein is the hinge point of the alternative and lectin complement activation pathway.

Three months after TAVI, C3a levels were significantly increased compared with baseline levels (baseline, $7.8 \mu \mathrm{g} /$ 
TABLE 2. Clinical and echocardiographic data

\begin{tabular}{|c|c|c|c|c|c|c|}
\hline \multirow[b]{2}{*}{ Variable } & \multicolumn{3}{|c|}{ TAVI } & \multicolumn{3}{|c|}{ MitraClip* } \\
\hline & Baseline & $>3 \mathrm{mo}$ & $P$ value & Baseline & $>3 \mathrm{mo}$ & $P$ value \\
\hline \multicolumn{7}{|l|}{ Clinical } \\
\hline NT-proBNP (pg/mL) & $1716.0(916.7,4764.5)$ & $1091(760.5,3388.0)$ & .050 & $2979.5(1107.0,7320.7)$ & $1060.0(635.0,2984.0)$ & .314 \\
\hline Creatinine (mg/dL) & $1.0(0.93,1.6)$ & $1.0(0.74,1.3)$ & .008 & $1.1(0.95,1.8)$ & $1.3(1.0,2.0)$ & .173 \\
\hline NYHA functional class $\geq$ III & $22(81.5)$ & $2(7.2)$ & .001 & $7(70)$ & $1(10)$ & .002 \\
\hline \multicolumn{7}{|l|}{ Echocardiographic parameters } \\
\hline LVEF $>55 \%$ & $14(51.9)$ & $17(63.0)$ & & $4(40)$ & $4(40)$ & \\
\hline LVEF $54 \%-45 \%$ & $5(18.5)$ & $7(25.9)$ & .033 & $1(10)$ & $3(30)$ & .157 \\
\hline LVEF $44 \%-30 \%$ & $4(14.8)$ & $3(11.1)$ & & $4(40)$ & $2(20)$ & \\
\hline LVEF $<30 \%$ & $4(14.8)$ & $0(0)$ & & $1(10)$ & $1(10)$ & \\
\hline sPAP $(\mathrm{mm} \mathrm{Hg})$ & & & & $64.0(51.2,78.2)$ & $41.0(30.0,51.0)$ & .285 \\
\hline AV PPG & $76.0(65.5,111.0)$ & $16.5(12.0,26.5)$ & .001 & & & \\
\hline AV MPG & $45.5(41.7,62.5)$ & $9.5(6.0,15.0)$ & .001 & & & \\
\hline AV Vmax & $4.6(4.0,5.5)$ & $1.8(1.6,2.2)$ & .018 & & & \\
\hline AVA $\left(\mathrm{cm}^{2}\right)$ & $0.7(0.6,0.85)$ & - & - & & & \\
\hline
\end{tabular}

Significant $P$ values were written in boldface. Values are presented as median (25th percentile, 75 th percentile) or n (\%). TAVI, Transcatheter aortic valve replacement; $N T$ proBNP, N-terminal pro-B-type natriuretic peptide; NYHA, New York Heart Association; $L V E F$, left ventricular ejection fraction; $s P A P$, systolic pulmonary artery pressure; $A V$, aortic valve; $P P G$, peak pressure gradient; $M P G$, mean pressure gradient; Vmax, maximum velocity; $A V A$, aortic valve area. *Abbott Laboratories, Abbott Park, Ill.

$\mathrm{mL}$; range, 3.2-37.9 $\mu \mathrm{g} / \mathrm{mL}$ vs 3-month TAVI, $37.2 \mu \mathrm{g} / \mathrm{mL}$; range, $4.6-89.3 \mu \mathrm{g} / \mathrm{mL} ; P=.001)$. In contrast, patients receiving the MitraClip procedure had lower C3a serum concentrations after intervention compared with baseline values (baseline, $16.5 \mu \mathrm{g} / \mathrm{mL}$; range, $5.7-48.5 \mu \mathrm{g} / \mathrm{mL}$ vs 3-month MitraClip, $6.3 \mu \mathrm{g} / \mathrm{mL}$; range, 3.1-45.3 $\mu \mathrm{g} / \mathrm{mL}$; $P=.130$ ). These data are evidence that the implantation of glutaraldehyde-fixed biological scaffolds augments the activation of complement pathways in vivo (Figure 2, A and $B$ ). There were no differences in C3a serum concentrations between bovine and porcine heart valves for TAVI (Table E4).

\section{Significantly Increased CitH3 Serum}

Concentrations, an Indicator of Granulocyte-Specific

NETosis, 3 Months After TAVI and MitraClip

\section{Implantation}

Neutrophils are an important cellular component of innate immunity. They play a critical role in microbial clearance, activation of other immune cells, and tissue damage and repair, and contribute to coagulation. Neutrophils are also involved in xenograft rejection. The presence of $\mathrm{CitH} 3$ in the serum is an accepted biological marker for the detection of granulocyte-specific NETosis. ${ }^{18}$ Three months after TAVI, CitH3 was significantly higher than baseline levels (baseline, $2.7 \mathrm{ng} / \mathrm{mL}$; range, 1.1-4.2 ng/mL vs 3-month TAVI, $3.9 \mathrm{ng} / \mathrm{mL}$; range, 1.3-9.7 ng/mL; $P=.025)$. Similar to the TAVI cohort, MitraClip patients also had significantly elevated $\mathrm{CitH} 3$ serum concentrations 3 months postintervention (baseline, $1.7 \mathrm{ng} / \mathrm{mL}$; range, 1.5 $5.2 \mathrm{ng} / \mathrm{mL}$ vs 3-month MitraClip, $2.9 \mathrm{ng} / \mathrm{mL}$; range, 1.5 $7.2 \mathrm{ng} / \mathrm{mL} ; P=.039$ ). These data indicate that TAVI, as well as MitraClip (to a lower extent) elicit NETosis in vivo (Figure 2, $C$ and $D$ ). There were no differences in citH3 serum concentrations between bovine and porcine heart valves for TAVI (Table E4).

\section{Significantly Increased sST2 but Not IL-33 Levels 3 Months After TAVI Implantation}

Secretion of sST2 is triggered by the cytokines IL- $1 \alpha$, IL$1 \beta$, and IL- 6 and contributes to the proinflammatory phase of systemic inflammation. ${ }^{19}$ IL-33 itself can upregulate

TABLE 3. Serum concentrations of galactose-alpha-1,3-galactose ( $\alpha$-Gal)-specific antibodies in transcatheter aortic valve replacement (TAVI) and MitraClip (Abbott Laboratories, Abbott Park, III) recipients

\begin{tabular}{|c|c|c|c|c|c|c|}
\hline \multirow[b]{2}{*}{ Antibody } & \multicolumn{3}{|c|}{ TAVI } & \multicolumn{3}{|c|}{ MitraClip } \\
\hline & Baseline & $>3 \mathrm{mo}$ & $P$ value & Baseline & $>3 \mathrm{mo}$ & $P$ value \\
\hline $\mathrm{IgG}$ & $11.5(4.6,14.9)$ & $13.3(6.4,15.8)$ & .09 & $12.7(7.2,16.0)$ & $8.0(5.4,12.4)$ & .193 \\
\hline IgG1 & $22.6(34.7,34.7)$ & $29.7(10.8,48.5)$ & .344 & $59.6(34.7,70)$. & $58.03(19.3,74.5)$ & .556 \\
\hline $\mathrm{IgG} 3$ & $5.3(3.0,4.6)$ & $23.1(6.1,34.1)$ & .002 & $21.8(3.4-46.0)$ & $6.3(2.3,20.7)$ & .232 \\
\hline IgG4 & $6.2(2.3,19.0)$ & $6.1(3.0,58.0)$ & .279 & $6.2(2.3-19.0)$ & $6.1(3.0,58.6)$ & .910 \\
\hline $\operatorname{IgE}$ & $0.51(0.36,1.1)$ & $0.56(0.42,1.1)$ & .284 & $1.4(0.32-7.7)$ & $0.57(0.27,2.2)$ & .460 \\
\hline
\end{tabular}

Significant $P$ values were written in boldface. Optical density values are reported as median (25th percentile, 75 th percentile). Ig, Immunoglobulin. 


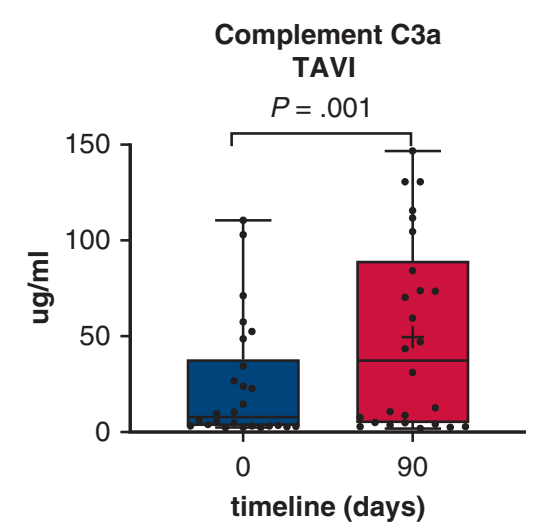

A

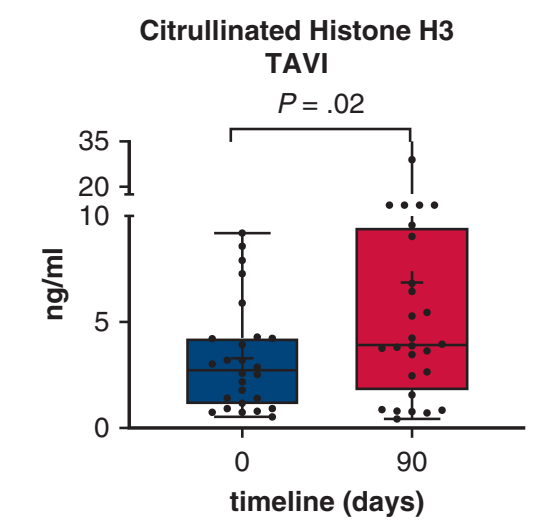

C

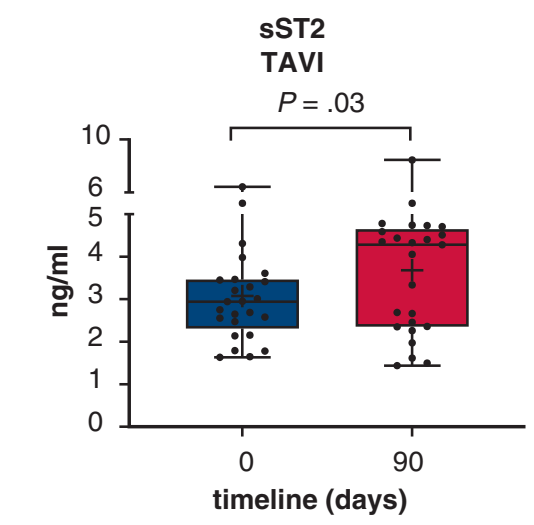

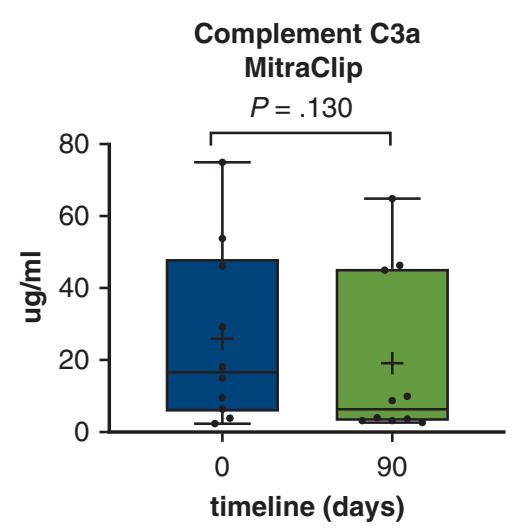

B
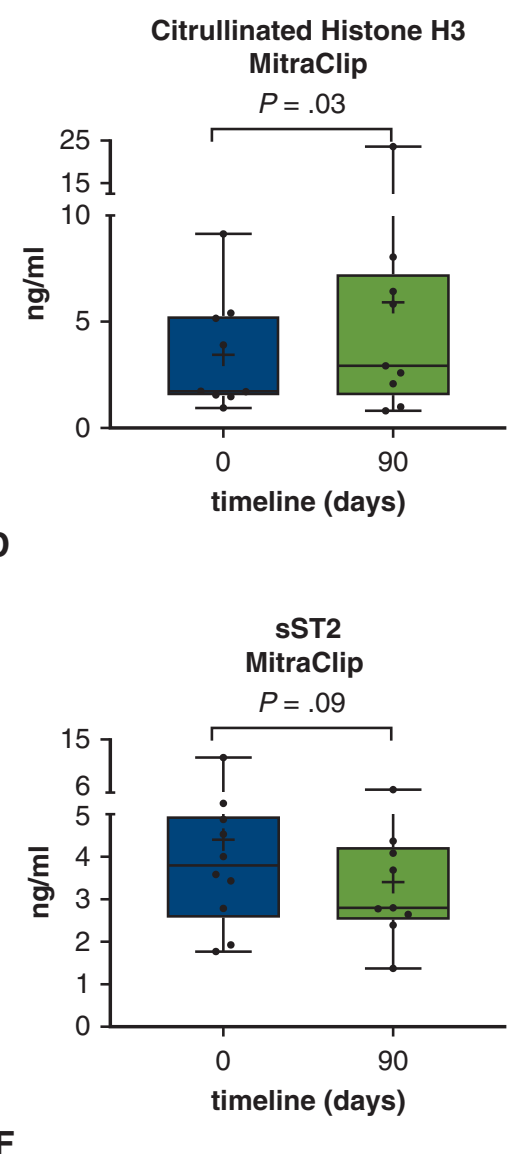

FIGURE 2. Significantly increased serum concentration of complement factor 3a (C3a), citrullinated H3 (CitH3), and soluble suppression of tumorigenicity-2 (sST2) 3 months after transcatheter aortic valve implantation (TAVI) compared with baseline levels. A, Three months after TAVI, C3a serum concentrations were significantly elevated compared to baseline levels. B, C3a serum concentrations did not increase 3 months after MitraClip (Abbott Laboratories, Abbott Park, Ill). C and D, Three months after TAVI and MitraClip, CitH3 serum concentrations were significantly upregulated compared with baseline levels. E and F, In TAVI patients, but not MitraClip patients, sST2 serum concentrations were significantly higher 3 months after intervention. For statistical analyses of serum concentrations between baseline levels and 3 months after TAVI or MitraClip the Wilcoxon matched-pairs signed-rank test was used.

expression of sST2. Aside from acting as a decoy receptor for IL-33, sST2 is believed to exhibit its antiinflammatory capacity directly via inhibition of Toll-like receptor signalling, ultimately resulting in the downregulation of nuclear factor-kappa B in macrophages. Currently sST2 and IL-33 are emerging as markers of systemic inflammation with prognostic capacity in many clinical entities (eg, polytrauma, sepsis, and food 
allergy). ${ }^{14,15,20}$ Here, TAVI increased sST2 significantly (baseline, $2.9 \mathrm{ng} / \mathrm{mL}$; range, $2.3-3.4 \mathrm{ng} / \mathrm{mL}$ vs 3-month TAVI, $4.3 \mathrm{ng} / \mathrm{mL}$; range, $2.3-4.7 \mathrm{ng} / \mathrm{mL} ; P=.039$ ) compared with MitraClip implantation (baseline, $3.7 \mathrm{ng} /$ $\mathrm{mL}$; range, $2.5-4.9 \mathrm{ng} / \mathrm{mL}$ vs 3-month MitraClip, $3.2 \mathrm{ng} /$ $\mathrm{mL}$; range, $2.5-4.8 \mathrm{ng} / \mathrm{mL} ; P=.09)$. IL-33 did not increase 3 months after TAVI or MitraClip compared with baseline levels (baseline, $25.58 \mathrm{pg} / \mathrm{mL}$; range, 14.36-46.15 pg/mL vs 3-month TAVI, $25.01 \mathrm{pg} / \mathrm{mL}$; range, $18.044-3.36 \mathrm{pg} /$ $\mathrm{mL} ; P=.728$ and baseline, $55.39 \mathrm{pg} / \mathrm{mL}$; range, 11.79 $806.0 \mathrm{pg} / \mathrm{mL}$ vs 3-month MitraClip, $17.92 \mathrm{pg} / \mathrm{mL}$; range, $10.68-516.7 \mathrm{pg} / \mathrm{mL} ; P=.670)$. These data show that $\alpha$ Gal-bearing biological scaffolds induce a systemic host immune activation relevant to the compensatory antiinflammatory response syndrome and allergic immune response (Figure 2, $E$ and $F$ ). There were no differences in SST2 serum concentrations between bovine and porcine heart valves for TAVI (Table E4).

\section{Clinical Outcome Data}

Within 3 months after intervention 5 TAVI patients were readmitted to the hospital. Three patients were readmitted due to postintervention complications: One patient required vascular surgery of a pseudoaneurysm of the femoral artery after arterial puncture. Another patient developed a thirddegree atrioventricular block and required a pacemaker implantation. Another patient was readmitted for gastrointestinal bleeding after receiving therapeutic anticoagulant therapy and aspirin. This patient received additional thromboembolic therapy due to atrial fibrillation and a coronary artery stent. The 2 noncardiology reasons for readmission were occurrence of a pseudoaneurysm in the left cubital artery after hemodialysis shunt graft implantation and dyspnea in a patient with a bronchial carcinoma. One MitraClip patient was readmitted for dyspnea. None of all included patients died within 3 months after TAVI/MitraClip intervention.

\section{DISCUSSION}

Here we demonstrate that TAVI elicits an up-regulation of $\alpha$-Gal-specific IgG3 mAbs, activates the complement system, induces NET formation, and causes increased sST2/IL-33 cytokine spillage in vivo.

These data provide evidence that $\alpha$-Gal-bearing medical devices are an ongoing inflammatory trigger. The link between $\alpha$-Gal-specific antibodies and humoral valve destruction has seemed obvious since 2005, but until recently, there was mere conjecture by informed surgeons and allergologists. ${ }^{4,5,21}$ Hawkins and colleagues ${ }^{22}$ recently described 2 patients who underwent implantation of a $\mathrm{BHV}$ and developed a postoperative meat allergy associated with an $\alpha$-Gal-specific IgE immune response. Both patients developed premature degeneration of the bioprosthesis that necessitated reoperation and implantation of a mechanical valve in the aortic position. ${ }^{22}$ This was the first clinical proof that $\alpha$-Gal on commercial BHVs and de novo development of $\alpha$-Gal-specific IgE antibodies can lead to biovalve degeneration.

Platts Mills, FRS, was among the first allergologists to propagate the idea that formation of $\alpha$-Gal-specific $\operatorname{IgE}$ is phenomenologically related to the development of meat allergy. ${ }^{23}$ Kollmann and colleagues ${ }^{17}$ extended this insight by showing that meat allergy is also associated with increased IgG, IgG1, and IgG3 directed against $\alpha$-Gal. Relevant to the above findings is the notion that $\alpha$-Gal-specific monoclonal antibodies remain rather stable in healthy humans. ${ }^{24}$ In this study, we provide evidence that, similar to surgically implanted bioprostheses, ${ }^{4,5}$ TAVI causes $\alpha$-Gal-specific IgG3 production as well as de novo production of $\alpha$-Galspecific IgE. None of our older patients developed the symptoms described in meat-allergic patients.

The complement system and NETosis are known to interact reciprocally. ${ }^{18}$ Opsonized antigens such as $\alpha$-Gal are recognized by complement receptors on neutrophils, which subsequently induce NETosis, whereas neutrophils activate complement factors, especially the anaphylatoxins $\mathrm{C} 3 \mathrm{a}$ and $\mathrm{C} 5 \mathrm{a}$, which can further alarm the immune system. ${ }^{25}$

Although our study found an $\alpha$-Gal-induced enhancement of the complement system and NET formation within 3 months after TAVI, both systems were already known to be activated in stenotic aortic valves. ${ }^{26}$ Helske and colleagues $^{27}$ found both elevated anaphylatoxin C3a and C5a levels and increased anaphylatoxin receptors, in particular $\mathrm{C} 3 \mathrm{a}$ receptor, in stenotic aortic valves in contrast to nonstenotic valves. ${ }^{27}$

Implanted foreign bodies comprising biological scaffolds for TAVI and mechanical devices for MitraClip are both lifesaving interventions with an increased risk of thrombogenicity and bleeding by inducing flow alterations. ${ }^{28}$ NETs activate the coagulation cascade directly and stimulate thrombosis in a platelet-dependent manner. ${ }^{29,30}$ In our study, demonstrated enhanced citH3 serum concentrations in TAVI and MitraClip patients and thereby emphasize the importance of therapeutic antithrombotic therapy with either dual antiplatelet therapy with aspirin and a P2Y12 receptor inhibitors or anticoagulation in a therapeutic dose for patients after TAVI and MitraClip procedures. ${ }^{31}$

We also found that, in parallel to the humoral immune response, sST2 is significantly increased after TAVI implantation in the presence of significantly improved left ventricular function (according to New York Heart Association functional classification) and lower levels of NT-proBNP. sST2 is a biomarker of adverse outcomes after myocardial infarction and heart failure as well as systemic inflammatory conditions. ${ }^{19,32,33}$ Our data, namely the increased sST2 levels 3 months after TAVI implantation with concomitantly reduced cardiac strain (as determined by lower levels of NT-proBNP), make it clear that sST2 may serve as a 
marker of inflammation rather than heart failure in TAVI patients.

In 1987, Galili and colleagues ${ }^{34}$ reported that the $\alpha$-Gal epitope is present on cells of all mammals except for humans and Old World monkeys. However, valve hemodynamic deterioration was associated with porcine tissue valve implantation in patients undergoing surgical valve implantation. In our study, we did not find any differences in cytokine serum concentrations and anti-Gal antibodies between patients receiving bovine compared with porcine BHVs for TAVI. We therefore assume that porcine and bovine biological scaffolds display similar immunogenic potential. Further studies with higher sample sizes are warranted to evaluate species-specific immune responses elicited by xenogenic implants.

The link between $\alpha$-Gal-specific inflammation and valve degeneration was determined through experimental work. Animal studies reported enhanced tissue calcification in rats and mice receiving $\alpha$-Gal-positive xenogenic tissue implantation. ${ }^{35,36}$ Our study group confirmed in humans short and midterm degradation of $\alpha$-Gal-bearing cells of surgical BHVs through exposure to the human blood circuit. Explanted cells were double fluorescence labeled with IB4 against $\alpha$-Gal residues and 4',6-diamidino-2-phenylindole (DAPI) against DNA to stain for nucleated cells. A BHV explanted 1 week after implantation contained IB4/DAPI positive cells within the collagen matrix. In 2 patients, who underwent reoperation after 12 months, porcine tissue showed a complete lack of IB4/DAPI positive cells. ${ }^{5}$

Clinical studies confirmed surgical BHV degeneration 15 years postoperatively in $60 \%$ to $70 \%$ of all patients older than age 75 years, whereas $100 \%$ of all implanted BHVs fail within 5 years in patients younger than age 35 years. ${ }^{37,38}$ Nevertheless, the 2017 Guidelines of the American Heart Association and the American College of Cardiology lowered the recommended age limit of BHV implantation to 50 years due to improved hemodynamic status, a lower risk of thromboembolic complications, and the absence of need for lifelong anticoagulant therapy compared with mechanical heart valves. ${ }^{39} \mathrm{Be}-$ sides, modern percutaneous valve-in-valve technologies provide less-invasive alternatives to treat potential BHV degeneration. ${ }^{40}$

We are convinced that TAVI will supersede surgical valve implantation in the future. Based on our data and data produced by others, currently utilized $\alpha$-Gal-bearing biological scaffolds must be optimized by the commercial medical device industry. Several promising techniques have been reported to potentially increase the longevity of BHVs. ${ }^{41,42}$ Already in 2013, treatment of BHVs with $\alpha$-galactosidase was used to effectively remove $\alpha$-Gal epitopes from both bovine and porcine tissues. ${ }^{35}$ Naso and colleagues ${ }^{43}$ introduced a preservation technique (ie, FACTA) that guarantees improved tissue biocompatibility by inactivating up to $95 \%$ of the $\alpha$-Gal epitopes and thereby reducing the propensity of BHVs to calcify.

Besides preservation techniques, there is growing interest in developing Gal-free BHVs from Gal-knockout pigs. Recently, Rahmani and colleagues ${ }^{44}$ used Gal-knockout pigs in engineering BHVs out of porcine pericardial leaflets with excellent hemodynamic parameters, long-term durability, and no thrombogenicity in a sheep model. Because BHVs for TAVI must be flexible, Gal-knockout pericardium xenografts seem to be favorable BHVs for TAVI to replace surgical aortic valve replacement in younger and lower-risk patients. Most recently, promising results of ongoing research concerning tissue-engineered heart valves for TAVI based on decellularized matrix in the pulmonary and aortic tissue were published. ${ }^{45}$

Our study has several limitations due to the limited sample size. We compared 2 different pathologies and surgical interventions: patients with aortic stenosis undergoing TAVI and patients with severe mitral regurgitation undergoing the MitraClip procedure. Due to the small sample size, we might have missed important demographic and immunological differences between groups. Further, we did not include patients after surgical aortic valve replacement as a control group. We could only draw our conclusions on similarities in the inflammatory response after surgical aortic valve replacement and TAVI patients due to prior research of our study group. ${ }^{4,5}$ Further, according to the current guidelines and institutional standards of the TAVI procedure, the median age of our study cohort was 78 years. We therefore cannot draw conclusions on systemic inflammatory responses in younger patients. In addition, determining immunological changes after prolonged follow-up periods might help to reveal whether these inflammatory changes will persist and have any effects on clinical outcomes and valve durability.

\section{CONCLUSIONS}

TAVI significantly improved left-ventricular function and reduced clinical symptoms in patients within 3 months after intervention. We present evidence that TAVI implantation elicits an $\alpha$-Gal-specific and unspecific humoral systemic inflammation that may influence BHV durability. We believe that the medical community should be cautioned against the uncritical lowering of age limits in recipients of $\alpha$-Gal-bearing TAVI devices. ${ }^{46}$

\section{Conflict of Interest Statement}

The authors reported no conflicts of interest.

The Journal policy requires editors and reviewers to disclose conflicts of interest and to decline handling or reviewing manuscripts for which they may have a conflict of interest. The editors and reviewers of this article have no conflicts of interest. 


\section{References}

1. Baumgartner H, Falk V, Bax JJ, De Bonis M, Hamm C, Holm P, et al. 2017 ESC/ EACTS Guidelines for the management of valvular heart disease. Eur Heart J. 2017;38:2739-91.

2. Siontis GCM, Overtchouk P, Cahill TJ, Modine T, Prendergast B, Praz F, et al. Transcatheter aortic valve implantation vs. surgical aortic valve replacement for treatment of symptomatic severe aortic stenosis: an updated meta-analysis. Eur Heart J. 2019;40:3143-53.

3. Mack MJ, Leon MB, Thourani VH, Makkar R, Kodali SK, Russo M, et al. Transcatheter aortic-valve replacement with a balloon-expandable valve in low-risk patients. N Engl J Med. 2019;380:1695-705.

4. Konakci KZ, Bohle B, Blumer R, Hoetzenecker K, Roth G, Moser G, et al. Alpha-Gal on bioprostheses: xenograft immune response in cardiac surgery. Eur J Clin Invest. 2005;35:17-23.

5. Mangold A, Szerafin T, Hoetzenecker K, Hacker S, Lichtenauer M, Niederpoldet T, et al. Alpha-Gal specific IgG immune response after implantation of bioprostheses. Thorac Cardiovasc Surg. 2009;57:191-5.

6. Park CS, Oh SS, Kim YE, Choi SY, Lim HG, Ahnet H, et al. Anti-alpha-Gal antibody response following xenogeneic heart valve implantation in adults. $J$ Heart Valve Dis. 2013;22:222-9.

7. Lim HG, Choi SY, Yoon EJ, Kim SH, Kim YJ. In vivo efficacy of alpha-galactosidase as possible promise for prolonged durability of bioprosthetic heart valve using alpha1,3-galactosyltransferase knockout mouse. Tissue Eng Part A. 2013;19:2339-48.

8. Zhou H, Hara H, Cooper DKC. The complex functioning of the complement system in xenotransplantation. Xenotransplantation. 2019;26:e12517.

9. Valenzuela NM, Reed EF. Antibody-mediated rejection across solid organ transplants: manifestations, mechanisms, and therapies. J Clin Invest. 2017;127: 2492-504.

10. Yoo HJ, Kim JE, Gu JY, Lee SB, Lee HJ, Hwang HY, et al. Porcine endothelium induces DNA-histone complex formation in human whole blood: a harmful effect of histone on coagulation and endothelial activation. Xenotransplantation. 2016; 23:464-71.

11. Wang HT, Maeda A, Sakai R, Lo PC, Takakura C, Jiaravuthisan P, et al. Human CD31 on porcine cells suppress xenogeneic neutrophil-mediated cytotoxicity via the inhibition of NETosis. Xenotransplantation. 2018;25:e12396.

12. Doring Y, Libby P, Soehnlein O. Neutrophil extracellular traps participate in cardiovascular diseases: recent experimental and clinical insights. Circ Res. 2020; 126:1228-41.

13. Nija RJ, Sanju S, Sidharthan N, Mony U. Extracellular trap by blood cells: clinical implications. Tissue Eng Regen Med. 2020;17:141-53.

14. Brunner M, Krenn C, Roth G, Moser B, Dworschak M, Jensen-Jarolim E, et al. Increased levels of soluble ST2 protein and $\operatorname{IgG} 1$ production in patients with sepsis and trauma. Intensive Care Med. 2004;30:1468-73.

15. Haider T, Simader E, Hacker P, Ankersmit HJ, Heinz T, Hajdu S, et al. Increased serum concentrations of soluble ST2 are associated with pulmonary complications and mortality in polytraumatized patients. Clin Chem Lab Med. 2018;56: 810-7.

16. Liew FY, Girard JP, Turnquist HR. Interleukin-33 in health and disease. Nat Rev Immunol. 2016;16:676-89.

17. Kollmann D, Nagl B, Ebner C, Emminger W, Wöhrl S, Kitzmüller C, et al. The quantity and quality of alpha-gal-specific antibodies differ in individuals with and without delayed red meat allergy. Allergy. 2017;72:266-73.

18. de Bont CM, Boelens WC, Pruijn GJM. NETosis, complement, and coagulation: a triangular relationship. Cell Mol Immunol. 2019;16:19-27.

19. Mildner M, Storka A, Lichtenauer M, Mlitz V, Ghannadan M, Hoetzenecker K, et al. Primary sources and immunological prerequisites for sST2 secretion in humans. Cardiovasc Res. 2010;87:769-77.

20. Untersmayr E, Bakos N, Scholl I, Kundi M, Roth-Walter F, Szalai K, et al. Antiulcer drugs promote IgE formation toward dietary antigens in adult patients. FASEB J. 2005; 19:656-8.

21. Platts-Mills TAE, Commins SP, Biedermann T, van Hage M, Levin M, Beck LA, et al. On the cause and consequences of IgE to galactose-alpha-1,3-galactose: a report from the National Institute of Allergy and Infectious Diseases Workshop on Understanding IgE-mediated mammalian meat allergy. J Allergy Clin Immunol. 2020;145:1061-71.

22. Hawkins RB, Frischtak HL, Kron IL, Ghanta RK. Premature Bioprosthetic aortic valve degeneration associated with allergy to galactose-alpha-1,3-galactose. $J$ Card Surg. 2016;31:446-8.

23. Commins SP, Satinover SM, Hosen J, Mozena J, Borish L, Lewis BD, et al. Delayed anaphylaxis, angioedema, or urticaria after consumption of red meat in pa- tients with IgE antibodies specific for galactose-alpha-1,3-galactose. J Allergy Clin Immunol. 2009;123:426-33.

24. Mangold A, Lebherz D, Papay P, Liepert J, Hlavin G, Lichtenberger C, et al. Anti-Gal titers in healthy adults and inflammatory bowel disease patients. Transplant Proc. 2011;43:3964-8.

25. Guglietta S, Chiavelli A, Zagato E, Krieg C, Gandini S, Ravenda PS, et al. Coagulation induced by C3aR-dependent NETosis drives protumorigenic neutrophils during small intestinal tumorigenesis. Nat Commun. 2016;7:11037.

26. Kopytek M, Kolasa-Trela R, Zabczyk M, Undas A, Natorska J. NETosis is associated with the severity of aortic stenosis: Links with inflammation. Int J Cardiol. 2019;286:121-6.

27. Helske S, Oksjoki R, Lindstedt KA, Lommi J, Turto T, Werkkala K, et al. Complement system is activated in stenotic aortic valves. Atherosclerosis. 2008;196: 190-200.

28. Nusca A, Bressi E, Colaiori I, Miglionico M, Di Sciascio G. Antiplatelet therapy in valvular and structural heart disease interventions. Cardiovasc Diagn Ther. 2018;8:678-93.

29. Gould TJ, Vu TT, Swystun LL, Dwivedi DJ, Mai SHC, Weitz JI, et al. Neutrophil extracellular traps promote thrombin generation through platelet-dependent and platelet-independent mechanisms. Arterioscler Thromb Vasc Biol. 2014;34:1977-84.

30. Ducci A, Tzamtzis S, Mullen MJ, Burriesci G. Hemodynamics in the Valsalva sinuses after transcatheter aortic valve implantation (TAVI). J Heart Valve Dis 2013;22:688-96.

31. Mitsios A, Chrysanthopoulou A, Arampatzioglou A, Angelidou I, Vidali V, Ritis K, et al. Ticagrelor exerts immune-modulatory effect by attenuating neutrophil extracellular traps. Int J Mol Sci. 2020;21.

32. Weinberg EO, Shimpo M, De Keulenaer GW, MacGillivray C, Tominaga S Solomon S, et al. Expression and regulation of ST2, an interleukin-1 receptor family member, in cardiomyocytes and myocardial infarction. Circulation. 2002;106:2961-6.

33. Griesenauer B, Paczesny S. The ST2/IL-33 axis in immune cells during inflammatory diseases. Front Immunol. 2017;8:475.

34. Galili U, Clark MR, Shohet SB, Buehler J, Macher BA. Evolutionary relationship between the natural anti-Gal antibody and the Gal alpha $1-3 \mathrm{Gal}$ epitope in primates. Proc Natl Acad Sci U S A. 1987;84:1369-73.

35. Lila N, McGregor CG, Carpentier S, Rancic J, Byrne GW, Carpentier A. Gal knockout pig pericardium: new source of material for heart valve bioprostheses J Heart Lung Transplant. 2010;29:538-43.

36. Kim MS, Lim HG, Kim YJ. Calcification of decellularized and alpha-galactosidase-treated bovine pericardial tissue in an alpha-Gal knock-out mouse implantation model: comparison with primate pericardial tissue. Eur J Cardiothorac Surg. 2016;49:894-900.

37. Schoen FJ, Levy RJ. Founder's Award, 25th Annual Meeting of the Society for Biomaterials, perspectives. Providence, RI, April 28-May 2, 1999. Tissue heart valves: current challenges and future research perspectives. J Biomed Mater Res. 1999;47:439-65.

38. Hammermeister K, Sethi GK, Henderson WG, Grover FL, Oprian C, Rahimtoola SH. Outcomes 15 years after valve replacement with a mechanical versus a bioprosthetic valve: final report of the Veterans Affairs randomized trial. J Am Coll Cardiol. 2000;36:1152-8.

39. Nishimura RA, Otto CM, Bonow RO, Carabello BA, Erwin JP, Fleisher LA, et al 2017 AHA/ACC focused update of the 2014 AHA/ACC guideline for the man agement of patients with valvular heart disease: a report of the American College of Cardiology/American Heart Association Task Force on Clinical Practice Guidelines. Circulation. 2017;135:e1159-95.

40. Scholtz S, Piper C, Horstkotte D, Gummert J, Ensminger SM, Börgermann J, et al. Valve-in-valve transcatheter aortic valve implantation with CoreValve/Evolut $\mathrm{R}((\mathrm{c}))$ for degenerated small versus bigger bioprostheses. J Interv Cardiol. 2018;31:384-90.

41. Naso F, Gandaglia A, Bottio T, Tarzia V, Nottle MB, d'Apice AJF, et al. First quantification of alpha-Gal epitope in current glutaraldehyde-fixed heart valve bioprostheses. Xenotransplantation. 2013;20:252-61.

42. Nerem RM. Cellular engineering. Ann Biomed Eng. 1991;19:529-45.

43. Naso F, Stefanelli U, Buratto E, Lazzari G, Perota A, Galli C, et al. Alpha-Gal inactivated heart valve bioprostheses exhibit an anti-calcification propensity similar to knockout tissues. Tissue Eng Part A. 2017;23:1181-95.

44. Rahmani B, McGregor C, Byrne G, Burriesci G. A durable porcine pericardia surgical bioprosthetic heart valve: a proof of concept. J Cardiovasc Transl Res. 2019;12:331-7.

45. Kim GB, Song MK, Bae EJ, Park EA, Lee W, Lim HG, et al. Successful feasibility human trial of a new self-expandable percutaneous pulmonary valve 
(pulsta valve) implantation using knitted nitinol wire backbone and trileaflet alpha-Gal-free porcine pericardial valve in the native right ventricular outflow tract. Circ Cardiovasc Interv. 2018;11:e06494.

46. Belluschi I, Buzzatti N, Gastiglioni A, Bonis MD, Montorfano M, Alfieri O, et al Severe aortic stenosis in the young, with or without biscupid valve: is transcath- eter aortic valve implantation the first choice? Eur Heart J Suppl. 2020;22(Suppl L):L1-5.

Key Words: TAVI, alpha Gal, NETosis, complement activation, bioprosthetic heart valves, MitraClip, ST2 
TABLE E1. Implanted medical devices for transcatheter aortic valve implantation and MitraClip (Abbott Laboratories, Abbott Park, III)

\begin{tabular}{lll}
\hline \multicolumn{1}{c}{ Device } & n & Bovine/porcine \\
\hline $\begin{array}{l}\text { Transcatheter heart valves } \\
\text { Edwards, Sapien 3 Ulta transcatheter aortic }\end{array}$ & 10 & Bovine \\
$\quad$ valve & & \\
$\quad \begin{array}{l}\text { Medtronic, CoreValve Evolut PRO } \\
\text { transcatheter aortic valve }\end{array}$ & 4 & Porcine \\
$\quad$ Boston Scientific, ACURATE neo Aortic & 8 & Porcine \\
$\quad$ Valve & & \\
$\begin{array}{l}\text { Abbott, Portico valve } \\
\text { St Jude Medical, Portico valve }\end{array}$ & 1 & Porcine \\
MitraClip devices & 4 & Porcine \\
Edwards, PASCAL transcatheter valve & 2 & \\
$\quad$ repair system & & \\
Abbott, MitraClip XTR Clip Delivery & 5 & \\
$\quad$ System & & \\
Abbott, MitraClip NTR Clip Delivery & 3 & \\
$\quad$ System & & \\
\hline
\end{tabular}

TABLE E2. Baseline inflammatory conditions in patients with hyperlipidemia and adult-onset diabetes mellitus

\begin{tabular}{|c|c|c|c|}
\hline Hyperlipidemia & Yes & No & $P$ value \\
\hline IgG (OD) & $11.6(3.2,14.9)$ & $11.7(5.1,15.8)$ & .710 \\
\hline IgG1 (OD) & $27.3(8.5,70.6)$ & $38.2(15.1,70.8)$ & .477 \\
\hline IgG3 (OD) & $2.3(2.0,6.8)$ & $2.0(1.7,4.8)$ & .115 \\
\hline $\operatorname{IgE}(\mathrm{OD})$ & $0.5(0.4,2.0)$ & $0.9(0.3,1.6)$ & .988 \\
\hline $\mathrm{sST} 2(\mathrm{ng} / \mathrm{mL})$ & $2.8(2.2,3.5)$ & $3.4(2.6,4.3)$ & .414 \\
\hline $\mathrm{c} 3 \mathrm{a}(\mu \mathrm{g} / \mathrm{mL})$ & $12.1(3.1,30.5)$ & $10.5(3.8,53.7)$ & .496 \\
\hline citH3 (ng/m) & $2.8(1.4,6.2)$ & $2.8(1.1,4.2)$ & .567 \\
\hline \multicolumn{4}{|l|}{$\begin{array}{l}\text { Adult-onset } \\
\text { diabetes } \\
\text { mellitus }\end{array}$} \\
\hline $\operatorname{IgG}(\mathrm{OD})$ & $12.6(6.6,14.8)$ & $11.7(4.6,15.6)$ & .832 \\
\hline IgG1 (OD) & $33.7(19.3,70.6)$ & $38.2(2.9,70.7)$ & .564 \\
\hline IgG3 (OD) & $2.1(1.8,3.9)$ & $2.4(1.8,6.4)$ & .496 \\
\hline $\operatorname{IgE}(\mathrm{OD})$ & $0.6(0.4,1.7)$ & $0.5(0.3,1.8)$ & .564 \\
\hline sST2 (ng/mL) & $3.2(2.6,4.4)$ & $2.7(0.0,3.5)$ & .330 \\
\hline $\mathrm{c} 3 \mathrm{a}(\mu \mathrm{g} / \mathrm{mL})$ & $12.1,(4.3,53.7)$ & $10.5(3.2,34.3)$ & .523 \\
\hline citH3 (ng/mL) & $2.8(1.3,6.7)$ & $2.8(1.4,5.1)$ & .542 \\
\hline
\end{tabular}


TABLE E3. Fold increase of serum cytokine levels and galactose-alpha-1,3-galactose-specific antibodies in patients with hyperlipidemia and adultonset diabetes mellitus

\begin{tabular}{lccc}
\hline \multicolumn{1}{c}{ Hyperlipidemia } & Yes & No & \multicolumn{1}{c}{$\boldsymbol{P}$ value } \\
\hline IgG & $1.7(-19.5,56.9)$ & $-3.1(-22.5,19.9)$ & .386 \\
IgG1 & $-8.1(-52.1,16.7)$ & $-1.5(-48.6,30.5)$ & 1.000 \\
IgG3 & $40.0(-13.2,92.5)$ & $13.5(-3.5,47.7)$ & .496 \\
IgE & $16.0(-34.1,63.7)$ & $-2.0(-17.6,72.7)$ & .781 \\
sST2 & $25.3(-20.5,74.2)$ & $-1.9(-28.5,38.6)$ & .224 \\
c3a & $29.3(-66.0,62.0)$ & $3.4(-16.0,48.5)$ & .926 \\
citH3 & $20.6(-17.9,61.8)$ & $11.4(-17.0,68.1)$ & \\
Adult-onset diabetes mellitus & & & .710 \\
IgG & $5.1(-20.6,52.4)$ & $-3.5(-22.2,20.8)$ & \\
IgG1 & $0.0(-36.9,10.9)$ & $-11.4(-49.9,47.0)$ & \\
IgG3 & $51.0(-3.9,155.0)$ & $13.5(-17.9,47.7)$ & \\
IgE & $30.3(-17.1,30.3)$ & $-2.0(-61.3,39.2)$ & .564 \\
sST2 & $26.1(-24.8,48.9)$ & $-3.5(-22.2,20.8)$ & .145 \\
c3a & $20.4(-57.6,52.1)$ & $3.4(-21.0,63.4)$ & .083 \\
citH3 & $33.9(-12.8,72.1)$ & $11.4(-19.7,40.0)$ & .704 \\
\hline
\end{tabular}

Values are reported as median (25th percentile, 75 th percentile). Ig. Immunoglobulin; $O D$, optical density; $s S T 2$, soluble suppression of tumorigenicity-2; $c 3 a$, complement factor 3a; citH3, citrullinated H3.

TABLE E4. Differences in cytokine serum concentrations and galactose-alpha-1,3-galactose-specific antibodies between bovine and porcine heart valves for TAVI

\begin{tabular}{lccc}
\hline Variable & \multicolumn{1}{c}{ Bovine } & Porcine & $\boldsymbol{P}$ value \\
\hline IgG & $8.3(-3.8$ to 141.8$)$ & $1.4(-20.6$ to 53.9$)$ & .315 \\
IgG1 & $-5.6(-40.6$ to 46.1$)$ & $3.1(-98.1$ to 65.1$)$ & .953 \\
IgG3 & $43.5(-11.2$ to 101.8$)$ & $37.5(-1.6$ to 156.7$)$ & .841 \\
IgE & $-3.5(-58.6$ to 84.3$)$ & $3.1(-98.1$ to 65.1$)$ & .514 \\
sST2 & $19.7(-12.8$ to 32.7$)$ & $21.2(-17.2$ to 35.2$)$ & .777 \\
c3a & $-9.5(-12.8$ to 52.7$)$ & $45.5(10.0$ to 67.3$)$ & .056 \\
citH3 & $-0.4(-65.7$ to -33.7$)$ & $11.1(-14.1$ to 74.0$)$ & .176 \\
\hline
\end{tabular}

Values are reported as median (interquartile range). Ig, Immunoglobulin; $s S T 2$, soluble suppression of tumorigenicity-2; $33 a$, complement factor $3 \mathrm{a}$; citH3, citrullinated H3. 